\title{
Pro-apoptotic role of nuclear factor- $\kappa B$ in adriamycin-induced acute myocardial injury in rats
}

\author{
FANG WANG, HONGLI LI* ${ }^{*}$ HAOYING SHI ${ }^{*}$ and BAOGUI SUN \\ Department of Cardiology, Shanghai Jiaotong University Affiliated First People's Hospital, Shanghai 200080, P.R. China
}

Received July 19, 2011; Accepted October 12, 2011

DOI: $10.3892 / \mathrm{mmr} .2011 .636$

\begin{abstract}
Nuclear factor $\kappa \mathrm{B}(\mathrm{NF}-\kappa \mathrm{B})$ is activated by a wide range of inducers and is able to mediate gene transcription. We investigated the role of NF- $\mathrm{B}$ in adriamycin-induced myocardial injury in rats and its mechanism of action. A total of 30 male Wistar rats were randomly divided into 3 groups: control, anthracycline antibiotic adriamycin (ADR) and ADR + pyrrolidine dithiocarbamate (PDTC). Myocardial apoptosis was detected by TUNEL assay; myocardium p53 gene expression was examined by RT-PCR analysis; location and distribution of p53 was observed by immunohistochemical assay; myocardial expression of p53 protein was assessed by Western blot analysis and activity of NF- $\mathrm{NB}$ was evaluated by electrophoretic mobility shift assay. The binding activity of $N F-\kappa B$, myocardial apoptotic index and expression of p53 increased significantly in the ADR groups. All of these changes induced by ADR were inhibited by PDTC. It was concluded that $\mathrm{NF}-\kappa \mathrm{B}$ activation may be pro-apoptotic through regulation of the expression of p53 in adriamycin-induced myocardial injury.
\end{abstract}

\section{Introduction}

The anthracycline antibiotic adriamycin (ADR) is one of the most effective and useful antineoplastic agents for the treatment of hematological, as well as solid, malignancies $(1,2)$. However, its major adverse side effect is the frequent onset of acute and chronic myocardial injury $(3,4)$. Recent studies have shown that acute doxorubicin cardiotoxicity involved cardiomyocyte apoptosis (5). Several investigators have aimed to understand the signaling pathways responsible for ADR-induced apoptosis $(6,7)$. One of the major signaling

Correspondence to: Professor Baogui Sun, Department of Cardiology, Shanghai Jiaotong University Affiliated First People's Hospital, 100 Haining Road, Shanghai 200080, P.R. China

E-mail: baoguisun@yahoo.cn

*Contributed equally

Key words: adriamycin, nuclear factor- $\kappa \mathrm{B}$, pyrrolidine dithiocarbamate, myocardium, apoptosis pathways is the nuclear transcription factor nuclear factor $\kappa \mathrm{B}$ $(\mathrm{NF}-\kappa \mathrm{B})$.

$\mathrm{NF}-\kappa \mathrm{B}$ was first found in the nucleus of B-lymphocytes as a transcription factor that binds to an enhancer of the immunoglobulin $\kappa$-light chain gene. Since then, NF- $\kappa$ B has been identified in numerous cells and is found to be activated by a wide range of inducers, including cytokines, ultraviolet irradiation and chemotherapeutic agents, while pyrrolidine dithiocarbamate (PDTC) was found to selectively inhibit $\mathrm{NF}-\kappa \mathrm{B}$ activation (8). In quiescent cells, $\mathrm{NF}-\kappa \mathrm{B}$ is maintained as an inactive form in the cytoplasm where it is bound to $\mathrm{I} \kappa \mathrm{B}$ inhibitor proteins, which prevent $N F-\kappa B$ from entering the nuclei. Upon cellular activation by extracellular stimuli, I $\mathrm{B}$ is phosphorylated and proteolytically degraded by proteases. This proteolytic process causes the release and translocation of the NF- $\mathrm{B}$ complex into the nucleus, where it mediates gene transcription by binding to specific sequences in the promoter regions of its target genes. Products of these target genes initiate or regulate the inflammatory response, apoptosis and carcinogenesis. NF- $\mathrm{NB}$ has been shown to promote or inhibit programmed cell death $(9,10)$. The opposing effects of NF- $\kappa \mathrm{B}$ are thought to be dependent on cell type and/or on the nature of stimuli. Moreover, different activation pathways of $\mathrm{NF}-\kappa \mathrm{B}$ may mediate the expression of various proteins that promote or inhibit apoptosis. It remains unclear as to whether $\mathrm{NF}-\kappa \mathrm{B}$ plays an essential role in ADR-induced myocardial injury.

Apoptosis-related genes govern commitment of apoptosis (e.g. Fas, c-myc, p53, TRAF2, IAP and Bcl-2). p53 plays an essential role in the cellular response to DNA damage by managing a cell cycle checkpoint that is critical for preserving the integrity of the genome.p53 levels increase in cells exposed to DNA damaging agents including UV light, anticancer drugs and $\gamma$-irradiation.

In the present study, we investigated the role of $\mathrm{NF}-\kappa \mathrm{B}$ in adriamycin-induced myocardial injury in rats. Our results provide evidence that $\mathrm{NF}-\kappa \mathrm{B}$ activation is pro-apoptotic through regulating the expression of $\mathrm{p} 53$ in adriamycin-induced myocardial injury.

\section{Materials and methods}

Animals. Adult, male Wistar rats weighing 150-170 g (total $\mathrm{n}=30$ ) were purchased from the Central Animal Laboratory, The Second Affiliated Hospital of Harbin Medical University, China. The Wistar rats were randomly divided into 3 groups: 
control $(\mathrm{n}=10)$, ADR $(10 \mathrm{mg} / \mathrm{kg}, \mathrm{n}=10)$ and ADR + PDTC $(100 \mathrm{mg} / \mathrm{kg}, \mathrm{n}=10)$. The rats had free access to standard rodent chow and water, and $10 \mathrm{mg} / \mathrm{kg}$ of ADR (Wanle Co., Ltd., Shenzhen, China) was administered by intraperitoneal (i.p.) administration in the ADR group. Instead of ADR, the same volume of physiological saline was injected into the control rats. Rats in the ADR + PDTC group were injected with $100 \mathrm{mg} / \mathrm{kg}$ PDTC (Sigma, St. Louis, MO, USA) i.p. $1 \mathrm{~h}$ prior to administration of ADR $10 \mathrm{mg} / \mathrm{kg}$. Rats were sacrificed by exsanguination $48 \mathrm{~h}$ following the beginning of administration of ADR or saline.

Electrophoretic mobility shift assay. Nuclear extract was prepared according to the manufacturer's instructions included in the Nuclear Extract kit (Active Motif Co., USA). To detect NF- $\kappa$ B binding activity, the LightShift ${ }^{\circledR}$ Chemiluminescent EMSA kit (20148; Pierce Co., USA) was used. A double-stranded oligonucleotide with the sequence 5'-AGTTGAGGGGACTTTCCCAGGC-3'; 3'-TCAACT CCCCTGAAAGGGTCCG-5' that was end-labeled with digoxin was obtained from Shanghai Shenggong Co. (China). Gel Shift Assay was carried out according to the Gel Shift Assay Systems protocol (Pierce Co.).

In situ terminal deoxynucleotidyl transferase assay (TUNEL method). The fragmented DNA on the 3-mm sections was labeled with the ApopTag apoptosis detection kit (Roche, USA). Briefly, following pretreatment with proteinase $\mathrm{K}$, paraffin-fixed slides were incubated with the reaction mixture containing working solution of TdT and digoxigenin-conjugated dUTP for $1 \mathrm{~h}$ at $37^{\circ} \mathrm{C}$. Labeled DNA was detected by peroxidase-conjugated anti-digoxigenin conjugate antibody. The bound complex was stained with a DAB-based substrate. To quantitate the degree of apoptosis, apoptotic cells were counted by three independent observers blinded to the experimental protocol. The apoptotic index was expressed as the percentage of the total number of myocardial cells.

Reverse transcription-polymerase chain reaction analysis. Total RNA was extracted from fresh-frozen myocardium using the TRIzol reagent (Invitrogen, CA, USA). Complementary DNA (cDNA) was synthesized according to the manufacturer's instructions provided in the Reverse Transcription kit (Promega, Madison, WI, USA), and then cDNA was amplified with a Multiplex PCR kit (Takara, Japan) with the following primers: $\beta$-actin, sense: 5 '-gccctgaggagcacctgt-3'; antisense: 5'-acgctcggtcaggatcttca-3' (300 bp products); p53, sense: 5'-attctgcccaccacagcgac-3'; antisense: 5'-ccgtcaccatcagagcaacg-3' (464 bp products). Cycling parameters were as follows: A total of $30 \mathrm{sec}$ for annealing at $56^{\circ} \mathrm{C}$ and PCR amplification for 30 cycles. PCR products $(8 \mu \mathrm{l})$ were analyzed by electrophoresis on a $1.5 \%$ agarose gel. Further semiquantity of PCR product was determined by Kodak 2.0 software.

Immunohistochemical assay. Paraffin sections of the heart were deparaffinized, and endogenous peroxidase activity was inactivated with $3 \% \mathrm{H}_{2} \mathrm{O}_{2}$ for $10 \mathrm{~min}$. The primary antibody (rabbit anti-rat p53, Santa Cruz Biotechnology, CA, USA) or normal blocking serum was added and incubated overnight.

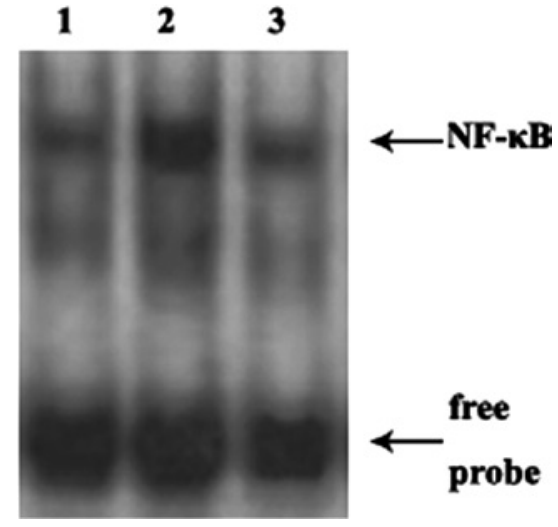

Figure 1. EMSA assay for nuclear factor $\kappa \mathrm{B}(\mathrm{NF}-\kappa \mathrm{B})$ activation in the rat hearts. Lane 1, control group; lane 2, ADR group (10 mg/kg); lane 3, anthracycline antibiotic adriamycin (ADR) + pyrrolidine dithiocarbamate (PDTC) group (100 mg/kg).

Biotin-conjugated goat anti-rabbit immunoglobulin $\mathrm{G}(\mathrm{IgG})$ was used as the secondary antibody and incubated for $30 \mathrm{~min}$. An avidin-biotin enzyme reagent was sequentially added and incubated for $20 \mathrm{~min}$. A peroxidase substrate was added and incubated until the desired stain intensity developed. Finally, cover sections with a glass coverslip were observed by light microscopy.

Western blot analysis. Proteins were extracted from fresh-frozen left ventricle myocardium. Heart tissues were homogenized and then lysed in a lysis buffer $(0.5 \%$ Nonidet P-40, 10 mM Tris- $\mathrm{HCl}$ (pH 7.5), $150 \mathrm{mM} \mathrm{NaCl}, 1 \mathrm{mM}$ phenylmethylsulfonyl fluoride and $5 \mathrm{mM}$ aprotinin) for $1 \mathrm{~h}$ at $4^{\circ} \mathrm{C}$. Protein extract (100 ng/lane) was run on a 10\% SDS-PAGE gel, and then transferred to a nitrocellulose membrane (Shanghai Huashun Co., China). The membrane was incubated with polyclonal rabbit anti-rat p53 antibody (Santa Cruz Biotechnology), diluted at 1:1000 and visualized by the ProtoBlot ${ }^{\circledR}$ II AP system (Promega).

\section{Results}

Electrophoretic mobility shift assay of $N F-\kappa B$ activation. The activation of NF- $\kappa \mathrm{B}$ was measured in terms of its DNA-binding activity. The $\mathrm{NF}-\kappa \mathrm{B}$ activation in the nuclear extracts was examined by EMSA. As shown in Fig. 1, ADR treatment induced activation of $\mathrm{NF}-\kappa \mathrm{B}$. To further investigate the change of $\mathrm{NF}-\kappa \mathrm{B}$ in ADR-induced myocardium injury, we used a $\mathrm{NF}-\kappa \mathrm{B}$ nonspecific inhibitor, PDTC. Rats were injected with PDTC and then treated with ADR. Pre-treatment with PDTC reversed the NF- $\mathrm{B}$ DNA-binding activity induced by ADR (Fig. 1). These findings suggest that ADR induces an increase in $N F-\kappa B$ activation and that PDTC inhibits ADR-induced $\mathrm{NF}-\kappa \mathrm{B}$ activation in rat hearts.

TUNEL assay for apoptosis. In general, cells undergoing apoptosis display a characteristic pattern of structural changes in the nucleus and cytoplasm, including rapid blebbing of plasma membrane and nuclear disintegration. The nuclear collapse is associated with extensive damage to chromatin and DNA-cleavage into oligonucleosomal length 

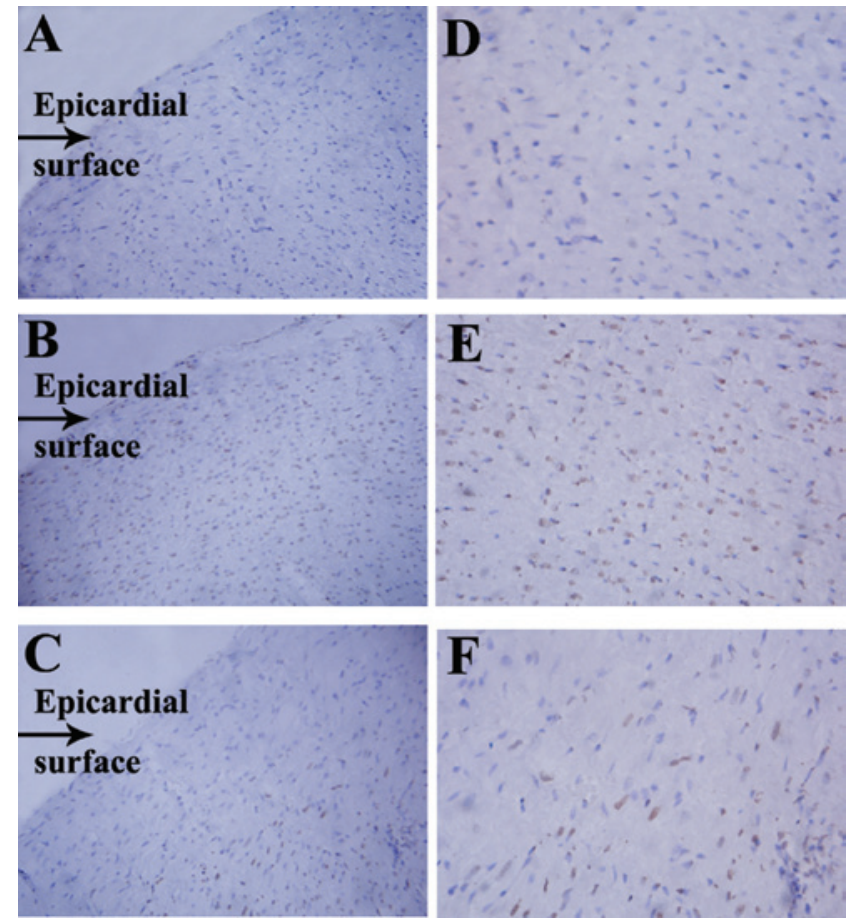

Figure 2. Myocardial apoptosis of rats. (A and D) Control group, (B and E) anthracycline antibiotic adriamycin (ADR) group $(10 \mathrm{mg} / \mathrm{kg})$ and (C and F) ADR + pyrrolidine dithiocarbamate (PDTC) group $(100 \mathrm{mg} / \mathrm{kg})$. (A-C) Representative images of TUNEL assay in the sections of cardiac tissue (magnification, x10). (D-F) Representative images of TUNEL assay in the sections of cardiac tissue at high magnification (x40) of A-C, respectively.
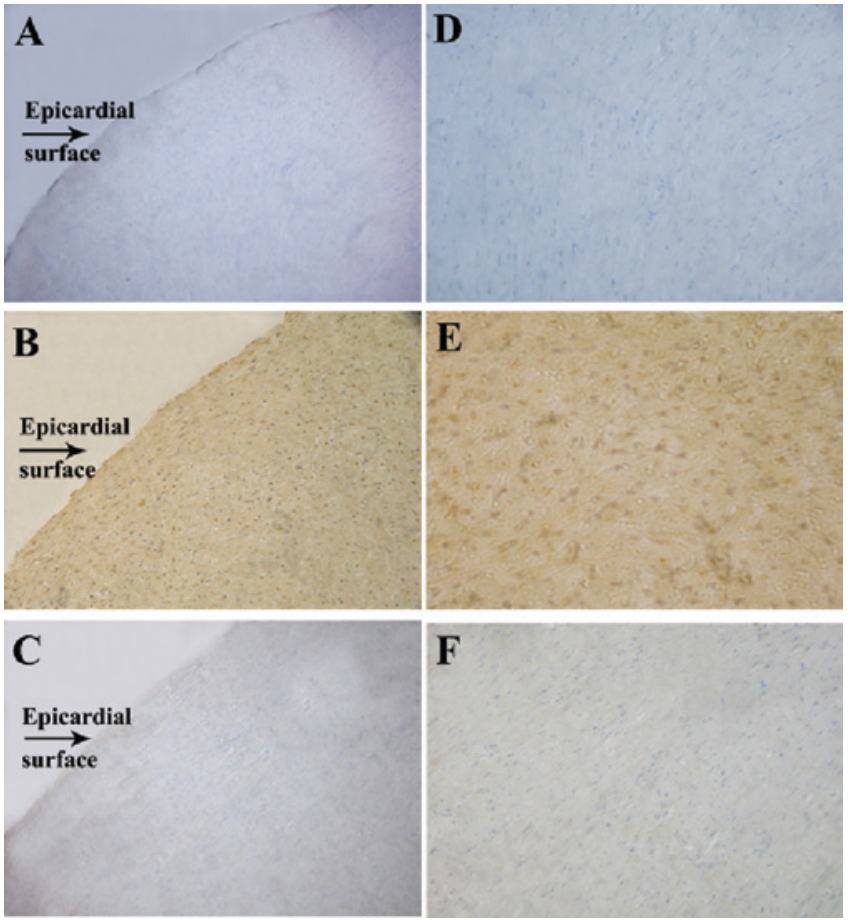

Figure 4. p53 immunohistochemistry of heart tissue in the rat groups. (A and D) Control group, (B and E) anthracycline antibiotic adriamycin (ADR) group $(10 \mathrm{mg} / \mathrm{kg})$ and $(\mathrm{C}$ and $\mathrm{F}) \mathrm{ADR}+$ pyrrolidine dithiocarbamate (PDTC) group (100 mg/kg). (A-C) Representative images of TUNEL assay in the sections of cardiac tissue (magnification, x10). (D-F) Representative images of TUNEL assay in sections of cardiac tissue at high magnification (x40) of A-C, respectively.

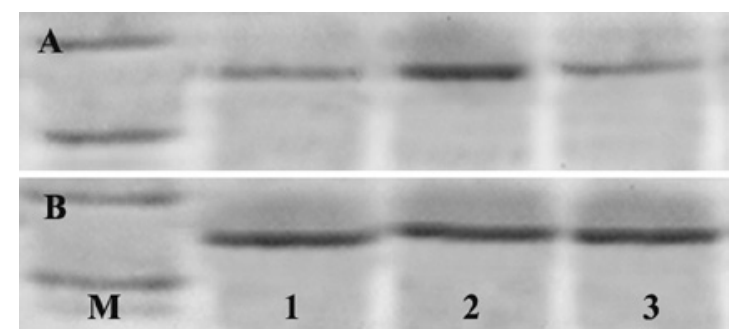

Figure 5. Western blot assay of the expression of (A) p53 and (B) $\beta$-actin proteins. M, marker; lane 1, control group; lane 2, anthracycline antibiotic adriamycin (ADR) group (10 mg/kg); lane 3, ADR + pyrrolidine dithiocarbamate (PDTC) group $(100 \mathrm{mg} / \mathrm{kg})$.

densitometry and normalized these to their corresponding $\beta$-actin bands. As shown in Fig. 3, ADR treatment was associated with an increase in p53 mRNA levels compared with the control group. A semi-quantitative study disclosed that ADR increased the p53: $\beta$-actin ratio. Increases in p53 mRNA levels following ADR challenge were prevented by PDTC treatment. A semi-quantitative study revealed that PDTC suppressed ADR-induced increases in the $\mathrm{p} 53: \beta$-actin ratio.

Location and distribution of the p53 protein. Immunohistochemistry was performed to determine the histological localization of p53 in the rat hearts. A control specimen revealed the trivial immunoreactivity for p53 (Fig. 4). By

contrast, there was a dramatic increase in staining for p53 changes in the expression of p53 mRNA in heart tissues were monitored by RT-PCR method. We quantified p53 bands by fragments. TUNEL methods were used to detect an theling of DNA strand breaks. TUNEL-positiv (Fig. 2). In response to ADR, induction of apoptotic cells was observed in rat hearts. To investigate the role of NF- $\kappa B$ in ADR-induced myocardial apoptosis, rats were injected with PDTC prior to ADR treatment. Pre-treatment with PDTC significantly inhibited the myocardium apoptosis induced by scattered under the epicardium.

Expression of the p53 gene. To determine the ability of $\mathrm{NF}-\kappa \mathrm{B}$ to regulate the expression of the p53 gene in the heart, 
and this was localized predominantly under the epicardial surface. p53 was slightly stained in the myocardium in the PDTC + ADR group.

Expression of the p53 protein. To determine the level of p53 induction in myocardium, the Western blot and semi-quantitative analyses using the NIH Image system for p53 were performed. The Western blotting with anti-rat p53 antibody revealed that levels of p53 were higher in the rats injected with ADR compared to the rats with physiological saline alone (Fig. 5). Pre-treatment with PDTC suppressed the expression of the $\mathrm{p} 53$ protein.

\section{Discussion}

In the present study, we determined a significant induction of myocardial apoptosis and NF- $\mathrm{kB}$ activation in the early phase following ADR administration in rats. PDTC as an inhibitor of NF- $\mathrm{KB}$ inhibited NF- $\mathrm{KB}$ activation and myocardial apoptosis. Activation of $\mathrm{NF}-\kappa \mathrm{B}$ mediated expression and translation of apoptosis-related gene, p53. These findings strongly suggest that NF- $\mathrm{BB}$ activation is pro-apoptotic through regulating the expression of p53 in adriamycin-induced myocardial injury.

The anthracycline antibiotic, ADR, is one of the most effective and useful antineoplastic agents for the treatment of hematological, as well as solid, malignancies $(1,2)$. However, its practical therapeutic use is sometimes limited by the not infrequent induction of acute cardiotoxicity $(3,4)$. Previous studies regarding the mechanisms of ADR cardiotoxicity have reported that the formation of free reactive oxygen radicals $(11,12)$, release of cardiotoxic cytokines $(13,14)$, cytoskeletal changes $(15)$ and intracellular calcium overload $(16,17)$ may be involved in the mechanisms of ADR cardiotoxicity. Recently, evidence has accumulated to suggest that apoptotic mechanisms are involved in acute and chronic myocyte loss in various heart disorders $(18,19)$. In this study, data revealed that acute ADR administration induces myocardial apoptosis in vivo. These results are in accordance with other studies (5). Several investigators have made efforts to understand the signaling pathways responsible for ADR-induced apoptosis $(6,7)$. One of the major signaling pathways is NF- $\mathrm{kB}$. Our results revealed that acute ADR administration induces NF- $\mathrm{KB}$ activation.

NF- $\mathrm{KB}$ has been reported to be involved in the regulation of ADR-induced apoptosis in various carcinomas, including T-cell lymphoma (20), melanoma (21), pancreatic (22), bladder (23) and breast cancer (24). Activation of $\mathrm{NF}-\kappa \mathrm{B}$ induced by ADR in tumor cells results in resistance to apoptosis. The present data provide evidence that NF- $\mathrm{kB}$ activation promotes ADR-induced apoptosis in the myocardium. Inhibition of NF-kB by PDTC was shown to inhibit ADR-induced myocardial apoptosis. Therefore, our data suggest that NF- $\mathrm{KB}$ activation is pro-apoptotic in adriamycininduced myocardial injury.

It appears that the role of NF- $\mathrm{KB}$ in apoptosis is quite complex and dependent on cell type and/or the nature of stimuli. Moreover, different activation pathways of NF- $\kappa B$ may mediate the expression of various proteins that promote or inhibit apoptosis. Several genes that may play a role in promoting apoptosis and whose expression is regulated by NF- $\kappa \mathrm{B}$ have been identified, including Fas ligand (25),
Fas (26) and c-Myc (27). Here, we reported that ADR is a potent inducer of $\mathrm{p} 53$ and NF- $\mathrm{\kappa B}$ transcription factors in the myocardium in a dose-related manner. Pre-treatment of rats with PDTC inhibited p53 expression and NF- $\kappa \mathrm{B}$ activation induced by ADR. Therefore, our data suggest that the proapoptotic role of NF-kB might be due to its direct regulation of p53, which is critical in mediating apoptotic signaling. Another proposed mechanism is that NF- $\mathrm{kB}$ down-regulates the expression of certain anti-apoptotic genes, for example Bcl-2 (28). In addition, the role of NF- $\kappa \mathrm{B}$ in managing the cell cycle could also be a mechanism for its pro-apoptotic effect (24).

In conclusion, the present study indicates that NF- $\mathrm{BB}$ activation is pro-apoptotic via regulation of the expression of p53 in adriamycin-induced myocardial injury. Regulation and control of NF- $\mathrm{KB}$ activation may be a powerful therapeutic strategy for reducing ADR-induced myocardial damage. In addition, controlled regulation of NF- $\mathrm{kB}$ activation possibly increases the sensitivity of tumor cells to antitumor therapy. However, intense research is required to further elucidate the role and function of this important nuclear factor in health and pathogenesis.

\section{References}

1. Abou-Alfa GK, Johnson P, Knox JJ, Capanu M, Davidenko I, Lacava J, Leung T, Gansukh B and Saltz LB: Doxorubicin plus sorafenib vs doxorubicin alone in patients with advanced hepatocellular carcinoma: a randomized trial. JAMA 304: 2154-2160, 2010.

2. Van Lummel M, van Blitterswijk WJ, Vink SR, Veldman RJ, van der Valk MA, Schipper D, Dicheva BM, Eggermont AM, ten Hagen TL, Verheij M and Koning GA: Enriching lipid nanovesicles with short-chain glucosylceramide improves doxorubicin delivery and efficacy in solid tumors. FASEB J 25: 280-289, 2011.

3. Hequet O, Le QH and Moullet I: Subclinical late cardiomyopathy after doxorubicin therapy for lymphoma in adults. J Clin Oncol 22: 1864-1871, 2004.

4. Lipshultz SE, Rifai N and Dalton VM: The effect of dexrazoxane on myocardial injury in doxorubicin-treated children with acute lymphoblastic leukemia. N Engl J Med 351: 145-153, 2004.

5. McTiernan CF: Fighting doxorubicin-induced cardiotoxicity with adiponectin. Cardiovasc Res 89: 262-264, 2011.

6. Soni H, Pandya G, Patel P, Acharya A, Jain M and Mehta AA: Beneficial effects of carbon monoxide-releasing molecule-2 (CORM-2) on acute doxorubicin cardiotoxicity in mice: role of oxidative stress and apoptosis. Toxicol Appl Pharmacol 253: 70-80, 2011.

7. Lou H, Danelisen I and Singal PK: Involvement of mitogen-activated protein kinases in adriamycin-induced cardiomyopathy. Am J Physiol Heart Circ Physiol 288: H1925-H1930, 2005.

8. Li H, Gu H and Sun B: Protective effects of pyrrolidine dithiocarbamate on myocardium apoptosis induced by adriamycin in rats. Int J Cardiol 114: 159-165, 2007.

9. Kim SB, Kim JS, Lee JH, et al: NF- $\kappa \mathrm{B}$ activation is required for cisplatin-induced apoptosis in head and neck squamous carcinoma cells. FEBS Lett 580: 311-318, 2006.

10. Chong ZZ, Li F and Maiese K: Erythropoietin requires NF- $\kappa B$ and its nuclear translocation to prevent early and late apoptotic neuronal injury during beta-amyloid toxicity. Curr Neurovasc Res 2: 387-399, 2005.

11. Cadeddu C, Piras A, Mantovani G, Deidda M, Dessì M, Madeddu C, Massa E and Mercuro G: Protective effects of the angiotensin II receptor blocker telmisartan on epirubicin-induced inflammation, oxidative stress, and early ventricular impairment. Am Heart J 160: 487.e1-e7, 2010.

12. Di X, Shiu RP, Newsham IF and Gewirtz DA: Apoptosis, autophagy, accelerated senescence and reactive oxygen in the response of human breast tumor cells to adriamycin. Biochem Pharmacol 77: 1139-1150, 2009. 
13. Mukherjee S, Banerjee SK, Maulik M, Dinda AK, Talwar KK and Maulik SK: Protection against acute adriamycin-induced cardiotoxicity by garlic: role of endogenous antioxidants and inhibition of TNF-alpha expression. BMC Pharmacol 3: 16, 2003.

14. Mohamed HE, Asker ME, Ali SI and Fattah TM: Protection against doxorubicin cardiomyopathy in rats: role of phosphodiesterase inhibitors type 4. Pharm Pharmacol 56: 757-768, 2004.

15. Dudnakova TV, Lakomkin VL, Tsyplenkova VG, Shekhonin BV, Shirinsky VP and Kapelko VI: Alterations in myocardial cytoskeletal and regulatory protein expression following a single doxorubicin injection. J Cardiovasc Pharmacol 41: 788-794, 2003.

16. RVitelli M, Filippelli A and Rinaldi B: Effects of docosahexaenoic acid on $\mathrm{Ca}^{2+}(\mathrm{i})$ increase induced by doxorubicin in ventricular rat cardiomyocytes. Life Sci 71: 1905-1916, 2002.

17. Zhou S, Heller LJ and Wallace KB: Interference with calcium-dependent mitochondrial bioenergetics in cardiac myocytes isolated from doxorubicin-treated rats. Toxicol Appl Pharmacol 175: 60-67, 2001.

18. Wu S, Ko YS and Teng MS: Adriamycin-induced cardiomyocyte and endothelial cell apoptosis: in vitro and in vivo studies. J Mol Cell Cardiol 34: 1595-1607, 2002.

19. Zhao W, Lu L, Chen SS and Sun Y: Temporal and spatial characteristics of apoptosis in the infarcted rat heart. Biochem Biophys Res Commun 325: 605-611, 2004.

20. Takada Y, Ichikawa H, Badmaev V and Aggarwal BB Acetyl-11-keto-beta-boswellic acid potentiates apoptosis, inhibits invasion, and abolishes osteoclastogenesis by suppressing $\mathrm{NF}-\kappa \mathrm{B}$ and NF- $\kappa \mathrm{B}$-regulated gene expression. J Immunol 176 3127-3140, 2006.

21. Bakker TR, Reed D, Renno T and Jongeneel CV: Efficient adenoviral transfer of $\mathrm{NF}-\kappa \mathrm{B}$ inhibitor sensitizes melanoma to tumor necrosis factor-mediated apoptosis. Int J Cancer 80: $320-323,1999$
22. Arlt A, Vorndamm J, Breitenbroich M, Folsch UR, Kalthoff H, Schmidt WE and Schafer H: Inhibition of NF- $\kappa$ B sensitizes human pancreatic carcinoma cells to apoptosis induced by etoposide (VP16) or doxorubicin. Oncogene 20: 859-868, 2001.

23. Sumitomo M, Tachibana M, Ozu C, Asakura H, Murai M, Hayakawa M, Nakamura H, Takayanagi A and Shimizu N: Induction of apoptosis of cytokine-producing bladder cancer cells by adenovirus-mediated IкBalpha overexpression. Hum Gene Ther 10: 37-47, 1999.

24. Ricca A, Biroccio A, Trisciuoglio D, Cippitelli M, Zupi G and Del Bufalo D: relA over-expression reduces tumorigenicity and activates apoptosis in human cancer cells. Br J Cancer 85: 1914-1921, 2001.

25. Brozovic S, Sahoo R, Barve S, Shiba H, Uriarte S, Blumberg RS and Kinane DF: Porphyromonas gingivalis enhances FasL expression via up-regulation of NFKB-mediated gene transcription and induces apoptotic cell death in human gingival epithelial cells. Microbiology 152: 797-806, 2006.

26. Peng Y, Gallagher SF, Haines K, Baksh K and Murr MM: Nuclear factor- $\kappa \mathrm{B}$ mediates Kupffer cell apoptosis through transcriptional activation of Fas/FasL. J Surg Res 130: 58-65, 2006.

27. Cavin LG, Wang F, Factor VM, Kaur S, Venkatraman M, Thorgeirsson SS and Arsura M: Transforming growth factoralpha inhibits the intrinsic pathway of c-Myc-induced apoptosis through activation of nuclear factor-kappaB in murine hepatocellular carcinomas. Mol Cancer Res 3: 403-412, 2005.

28. Aoki M, Nata T and Morishita R: Endothelial apoptosis induced by oxidative stress through activation of NF- $\mathrm{B}$ : antiapoptotic effect of antioxidant agents on endothelial cells. Hypertension 38: 48-55, 2001. 